\title{
Study of Plasma fibrinogen in pregnant women with severe preeclampsia
}

\author{
Alaa Fadhil Alwan MD ${ }^{1}$, Aladdin Mudhafar Zubair MD², \\ Shaymma Wahbi Salman $\mathrm{MD}^{3}$ \\ 1. Assistant prof. /National Center of Hematology/clinical department/Baghdad/Iraq \\ 2.Assistant prof. /Department of Pathology/Almustansiriya College of Medicine/ Baghdad/Iraq \\ 3. Senior registrar/laboratorydept. /Alyarmouk Teaching Hospital
}

\begin{abstract}
:
Background:Preeclampsia is a complication of pregnancy constituting a major cause of maternal and fatal morbidity and mortality.Pregnancy is a hypercoagulable state with changes in procoagulant, anticoagulant, and fibrinolytic systems. In preeclampsia, there is a shift in the haemostatic balance towards a pro-thrombotic state, together with changes in endothelial function. It is a state of enhanced coagulation as evidenced by an increased amount of clotting factors in maternal circulation.
\end{abstract}

Aim of the study:To study the changes in plasma fibrinogen in pregnant women suffering from severe preeclampsia in comparison with healthy normotensive pregnant women and to correlate its level with the severity of preeclampsia.

Patients and Methods:This study was carried out at Alyarmouk Teaching Hospital from July to October 2010.This study included thirty five pregnant women in the third trimester of pregnancy with severe preeclampsia.A total of thirty five healthy pregnant women who werenot in labour, their age and gestational age matchedwith the patients and normotensive throughout gestation were included as a control group.All patients gave their written informed consent before entering the studyBlood samples were taken from both groups for measurement ofFibrinogen. The student T-test and correlation coefficient study were used for statistical tests.

Results:There was significant difference inmean plasma fibrinogen between patients with severe preeclampsia

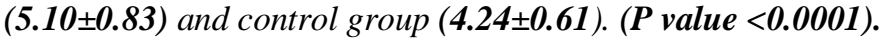

Conclusions:Plasma fibrinogen was significantly increased in patients with severe preeclampsia than control group and show significant direct linear correlation with the severity of preeclampsia.

Key word: fibrinogen, preeclampsia

\section{Introduction}

Fibrinogen is composed of six polypeptide chains (two $\alpha$-chains, two $\beta$-chains, and two $\mathrm{y}$ chains.It is found in plasma and in platelet alpha granules. ${ }^{[1]}$ Mean plasma level of $2.5 \mathrm{mg} / \mathrm{ml}{ }^{[2]}$ with a normal plasma halflife of 90 hours. ${ }^{[3]}$ Fibrinogen is considered to be an acute phase reactant, and as such, it is up-regulated two- to tenfold in response to a variety of physiologic stresses including trauma, pregnancy and tissue inflammation. ${ }^{[2]}$ Platelet aggregation critically depends on fibrinogen binding to activated platelets via the platelet fibrinogen receptor gpIIb-IIIa. Fibrin adhesion to stimulated platelets is also important in thrombus formation. ${ }^{[2]}$ Activation of the coagulation cascadeis usually associated with activation of the fibrinolyticsystem, and this is true for preeclampsia. $^{[4]}$

Itis known that normal pregnancy is a procoagulantstatus and that this tendency is increasingduring the development of the pregnancy withthe end-point of minimizing the blood loss intrapartum.In preeclamptic pregnancies, the coagulationcascade is generally activated. ${ }^{[4,5]}$

Preeclampsia (PE) being by itself a highly thrombotic and procoagulant state with platelet activationand consumption, promoting of thrombin and fibrin formation with destruction. ${ }^{[6]}$ The state of enhanced coagulation in preeclampsia was evidenced by elevated level of elevated levels of von Willebrand's factor $^{[4]}$, increased theconcentration of total fibrinogen ${ }^{[7]}$ and thepercentage of high molecular weight fibrinogen in preeclampsia as the activated maternal vascular endothelium also triggers a generalized intravascular inflammatory reaction. ${ }^{[8]}$ Plasma levels of fibrinogen vary according to both individual and inflammatory parameters. During normal pregnancy the plasma levels of fibrinogen increase, and in women with preeclampsia the fibrinogen levels are even higher. ${ }^{[9]}$ In addition to its importance for clot formation, fibrinogen also interacts with angiogenic factors such as fibroblast growth factor-2 and vascular endothelial growth factor (VEGF). It also binds to histidine-rich glycoprotein (HRG). ${ }^{[9]}$ 


\section{Aims of the study}

To study the changes in plasma fibrinogen, in pregnant women suffering from severe preeclampsia in comparison with healthy normotensive pregnant women and to correlate its level with the severity of preeclampsia.

\section{Patients and Methods}

This study was carried out at Alyarmouk Teaching Hospital from July to October 2010.Thirty five pregnant women in the third trimester of pregnancy with severe preeclampsia were included in this study. All patients gave their written informed consent before entering the study.The inclusion criteria for severe preeclampsia included sustained blood pressure of at least $160 / 110 \mathrm{mmHg}$ or higher with persistent proteinuria of $2+$ or greater on urine dipstick (each $1+$ is equal to $30 \mathrm{mg} / \mathrm{dl}$ ).

Any patient who had associated confounding conditions that could altered the coagulation tests such as placental abruption or previa, sepsis, stillborn or heavy vaginal bleeding and patients with a history of diabetes, renal disease, chronic hypertension, other cardiovascular illness and symptomatic infectious diseases or received anticoagulant drugs like aspirin or heparin were excluded from the study. A total of thirty fiveapparently healthy pregnant women who werenot in labour, normotensive throughout gestationwith their age and gestational age matchedwith the patients, were included as a control group.

Before receiving any medication blood samples were taken from each patient.1.8 mlof venous blood sample was collected using a clean aseptic venipuncture technique from each patient and put into a clean disposable capped plastic tube containing $0.2 \mathrm{ml}$ trisodium citrate dihydrate $32 \mathrm{~g} / \mathrm{L}$.

The tubes with citrated blood were centrifuged without delay at room temp $\left(20-25^{\circ} \mathrm{C}\right), 2500 \mathrm{~g}$ for 15 minutes to prepare platelet poor plasma for measurement of fibrinogen assay without delay.

Fresh plasma was obtained from healthy normotensive pregnant women ( 35 women) to be used as control group and was processed in the same way as the patients'samples.

Pooled fresh platelet poor plasma was obtained fromapparently normal healthy donors (other than the control group) andwas processed in the same way as the patients'samples. These are used for calibration curve.

\section{Fibrinogen assays (Clauss Technique): Principle:}

Quantitative determination of the fibrinogen level in the plasma by Clauss method.Diluted plasma is clotted with a strong thrombin solution; the plasma must be diluted to give a low level of any inhibitors (e.g., FDPs and heparin). A strong thrombin solution must be used so that the clotting time over a wide range is independent of the thrombin concentration. ${ }^{[3]}$ The Fibrinogen assay was determined using a commercially available kit (Diagnostica Stago/France).

Reagent 1:Fibri-Prest freeze-dried titrated human calcium thrombin containing a specific heparin inhibitor to allow the assay of fibrinogen in heparinized plasma samples.

Reagent 2: Owren-Koller buffer.PH=7.35.

\section{Calibration curve:}

The citrated platelet poor plasmaof control pool plasma was used and the following dilutions in Owren -Koller buffer were made:
Dilution:
$1: 5$
$1: 10 \quad 1: 20$

1. In plastic plane tube $0.8 \mathrm{ml}$ of Owren -Koller buffer $+0.2 \mathrm{ml}$ of control plasma to obtain a dilution of 1:5.

2. In each of a second and a third plastic plain tubes $0.5 \mathrm{ml}$ of Owren-Koller buffer was added.

3. In the second tube $0.5 \mathrm{ml}$ from the first tube was added to $0.5 \mathrm{ml}$ buffer to obtain a dilution of 1:10.

4. In the third tube $0.5 \mathrm{ml}$ from the second tube was added to the $0.5 \mathrm{ml}$ buffer to obtain a dilution of 1:20.

5. The dilutions and the time were plotted on a $\log$-log paper to obtain a straight line.

\section{Patient's plasma:}

Dilutions of the patients' plasma in Owren -Koller buffer were made exactly in the same way of that of the control plasma:

Dilution: $\quad 1: 5 \quad 1: 10 \quad 1: 20$

\section{Procedure:}

Manual procedure was used following the instructions of the manufacturer.

The test was performed in a glass tube(tubes measuring $75 \times 10 \mathrm{~mm}$ ) at $37^{\circ} \mathrm{C} \rightarrow$

- Test sample (standard, patient or control) $0.2 \mathrm{ml}$.

- Incubate at $37^{\circ} \mathrm{C}$ for 2 minute. 
- Add 'reagent 1 ' $0.1 \mathrm{ml}$ prewarmed at $37^{\circ} \mathrm{C}$, and start a stop watch.

- Note the clotting time (thin filament of fibrin appears).

Normal fibrinogen level is $2-4 \mathrm{~g} / \mathrm{L} .{ }^{(10)}$

Using log -log paper, clotting times (seconds) were plotted on the Y-axisand their corresponding fibrinogen level was plotted on the $\mathrm{X}$-axis, then the best fit calibration line was drawn. The times the test patients' plasmas had taken to clot and those of the controls were interpolated on the calibration line to determine their respective fibrinogen level .

In addition, Mean arterial pressure (MAP) was used as an indicator of the severity of the preeclampsia. MAP was calculated using thefollowing formula:

MAP $=[(2 \mathrm{X}$ diastolic blood pressure $)+$ systolic blood pressure $] / 3 .^{[7]}$

The student $\mathrm{T}$-test and correlation coefficient study were used for statistical tests.

\section{Results}

Thirty five pregnant women with sever preeclampsia were included in this study.Their ages were ranging from 18 to41 years with mean of 29.4 years. Table (1)shows age distribution and table (2) shows parity of patients.

Table 1: The age distribution of the preeclamptic patients.

\begin{tabular}{|c||c||c|}
\hline Age groups (years) & No. & \% \\
\hline $18-20$ & 4 & $11.4 \%$ \\
\hline $21-25$ & 5 & $14.3 \%$ \\
\hline $26-30$ & 11 & $31.4 \%$ \\
\hline $31-35$ & 8 & $22.9 \%$ \\
\hline $36-41$ & 7 & $20 \%$ \\
\hline
\end{tabular}

Table 2: The parity distribution of preeclamptic patients.

\begin{tabular}{|c||c||c|}
\hline Parity & No. & \% \\
\hline \hline Para 0 & 16 & $45.7 \%$ \\
\hline Para 1 & 8 & $22.9 \%$ \\
\hline Para 2 & 5 & $14.3 \%$ \\
\hline \hline Para 3 & 4 & $11.4 \%$ \\
\hline \hline Para 4 and more & 2 & $5.7 \%$ \\
\hline
\end{tabular}

Thirty five healthy normotensive pregnant women age and gestational age matched with patients were included as a control groups. Table 3 shows the clinical data on the preeclamptic women and healthy controls. The correlation between MAP and plasma fibrinogen is shown in figure 1.

Table 3: showing mean, standard deviation, range and $P$ value of different parameters in pregnant women with severe preeclampsia and control subjects.

\begin{tabular}{|c|c|c|c|c|c|}
\hline & \multicolumn{2}{|c|}{ Preeclampsia } & \multicolumn{2}{|c|}{ Control } & \multirow{2}{*}{$\begin{array}{c}\text { P value } \\
< \\
\end{array}$} \\
\hline & Mean \pm SD & Range & Mean \pm SD & Range & \\
\hline Age (years) & $29.40 \pm 6.60$ & $18-41$ & $30.80 \pm 6.54$ & $19-41$ & 0.376 \\
\hline $\begin{array}{c}\begin{array}{c}\text { Gestational age } \\
\text { (weeks) }\end{array} \\
\end{array}$ & $35.97 \pm 2.79$ & $30-40$ & $35.74 \pm 2.90$ & $30-40$ & 0.738 \\
\hline $\begin{array}{c}\text { Systolic blood } \\
\text { pressure }(\mathbf{m m H g})\end{array}$ & $174.42 \pm 15.84$ & $160-210$ & $112.00 \pm 9.0$ & $100-130$ & $0.0001 *$ \\
\hline $\begin{array}{c}\text { Diastolic blood } \\
\text { pressure }(\mathrm{mmHg})\end{array}$ & $114.57 \pm 5.19$ & $110-125$ & $66.71 \pm 7.56$ & $60-80$ & $0.0001 *$ \\
\hline $\begin{array}{c}\text { Mean arterial } \\
\text { pressure }(\mathbf{m m H g})\end{array}$ & $134.80 \pm 6.65$ & $127-150$ & $81.80 \pm 6.12$ & $73-93$ & $0.0001 *$ \\
\hline Fibrinogen (g/l) & $5.10 \pm 0.83$ & $3.5-6.5$ & $4.24 \pm 0.61$ & $3.3-5.3$ & $0.0001 *$ \\
\hline
\end{tabular}

$*=$ Statistically significant difference $(\mathrm{p}<0.05)$ from the controls. 


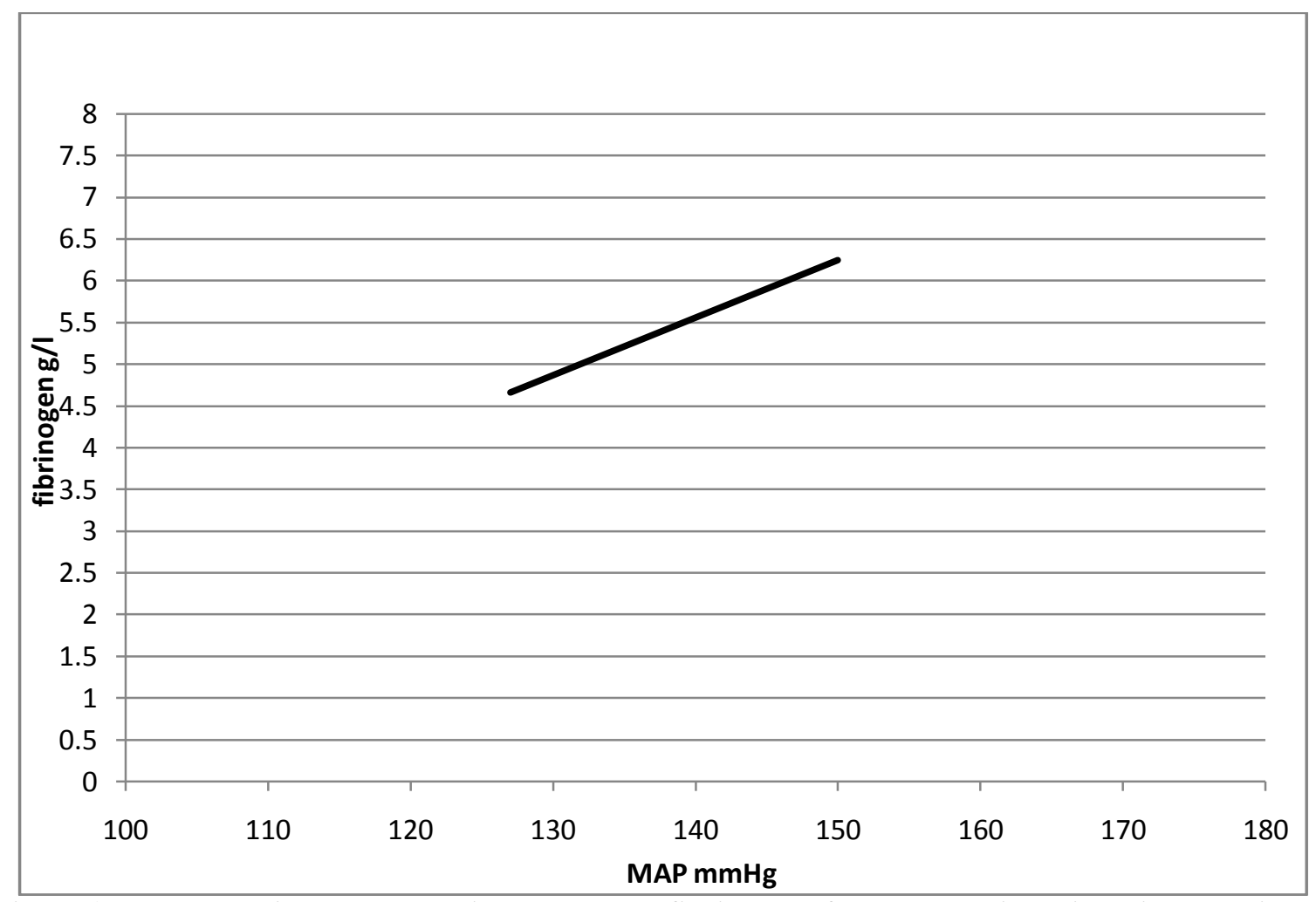

Figure 1:The correlation between MAP and plasma fibrinogen of pre-eclamptic patients included in the study $(P<0.001, r=0.537)$.

\section{Discussion}

Preeclampsia is associated with changes in the hemostatic system and endothelial status. ${ }^{[11]}$ Preeclampsia has been identified as a risk factorfor venous thromboembolism in several widelyavailable practice guidelines and is used as anidentifier of patients requiring prophylactic heparintreatment.$^{[12]}$

In this study, the role played by fibrinogen in normal pregnancyand preeclampsiawasevaluated and it was found that the level of fibrinogen in women with severe preeclampsia significantly higher than in control women, despite similar maternal and gestational age, this result is consistent with the results obtained by Ustun $\mathrm{Y}^{[7]}$,Manten GT.et al ${ }^{[8]}$ and Karehed k .et al. ${ }^{[9]}$

This study showed the correlation of fibrinogen levels with the severity of preeclampsia in which it was found that there was significant direct correlationbetween fibrinogen and MAP ( $\mathrm{P}$-value 0.001, $\mathrm{r}=0.537$ ). Fibrinogen was significantlyincreased with MAP as shown in figure 1. This result was similar to the result obtained by Ustun $\mathrm{Y}$ et al. ${ }^{[7]}$

Raised fibrinogen concentration is wellestablished as risk factors for thrombotic episodes in the general population. ${ }^{[13,14]}$ In pregnancy fibrinogen concentration is raised naturally, but the upper limit, above which the rise may be considered pathological, is uncertain.

This study supports the fact that, even in normal pregnancies, there is an elevated level of fibrinogen concentration but in severe preeclamptic women showed interestingly more elevation in their levels. As in other studies which showed similarresults. ${ }^{[15]}$

\section{Conclusions}

Plasmafibrinogen was significantly increased in patients with severe preeclampsia than control group and show significant direct linear correlation with the severity of preeclampsia.

\section{References}

[1]. Hoffman M., Roberts H.Molecular Biology and Biochemistry of the Coagulation Factors and Pathway of Hemostasis. In: Lichtman MA, Beutler E, Seligsohn U, Kipps T, Kaushansky K, Prchal J,editors .William's Haematology $.8^{\text {th }}$ ed. China The McGrawHill companies; 2010. Chapter 115.

[2]. Greenbery CS, Orther C. Blood coagulation and Fibrinolysis. In: Greer JP, Foerster J, Lukens JN, editors. Wintrobes Clinical Hematology. $11^{\text {th }}$ ed. Baltimone: William's and Wilkins. 2003; Chapter 21.

[3]. Laffan M, Manning R. Inv of hemostasis. In:Lewis SM, Bain BJ, Bates I, editors. Dacie and Lewis Practical Haematology. $10^{\text {th }}$ ed. Philadelphia: Churchill Livingstone Elsevier. 2006; 19:380-437. 
[4]. Heilmann L, Rath W, Pollow K. Hemostaticabnormalities in patients withsevere preeclampsia. Clin Appl ThrombHemost.2007; $13: 285-291$

[5]. Weiner CP .Preeclampsia-eclampsiasyndrome and coagulation. Clin Perinatol. 1991; 18:713-726.

[6]. Cunningham FG, Leveno KJ, BloomSL, Hauth JC, Gilstrap LC, WenstromKD. Hypertensive Disorders in Pregnancy. Williams Obstetrics. New York: McGraw-Hill; 2005:761-808.

[7]. Ustun Y, Engin-Ustun Y, Kamaci M. Association of fibrinogen and C-reactive protein with severity of preeclampsia. Eur J Obstet Gynecol Reprod Biol. 2005; 121:154-158.

[8]. Manten GT, Sikkema JM, Franx A, Hameeteman TM, Visser GH.Increased high molecular weight fibrinogen in preeclampsia. Thromb Res. 2003; 111:143-147.

[9]. Karehed K, Wikström AK, Olsson A, Larsson A, Matts OM, Akeru H. Fibrinogen and histidine-rich glycoprotein in early-onset preeclampsia. Acta Obstetricia et Gynecologica Scandinavica. 2010; 89: 131-139.

[10]. Samama M, Conard J, Horellou MH, LecompteT. physiologie et exploration de Ihemostate. Doin.1990:153-155.

[11]. Hayashi M, Inoue T, Hoshimoto K.Characterization of five markerlevels of the hemostatic system andendothelial status in normotensive pregnancy and preeclampsia. Eur J Haematol.2002; 69:297-302.

[12]. Higgins JR. Haemostasis in preeclampsia.Thromb Res. 2004; 119:1-96.

[13]. Tripodi A. Levels of coagulation factors and venous thromboembolism. Haematologica. 2003; 88: $705-711$.

[14]. Kamphuisen PW, Eikenboom JC, Vos HL, Pablo R, Sturk A, Bertina RM, et al. Increased levels of factor VIII and fibrinogen in patients with venous thrombosis are not caused by acute phase reactions. Thromb Haemost 1999; 81: 680-683.

[15]. Williams VK, Griffiths AB, Carbone S, Hague WM. Fibrinogen concentration and factor VIII activity in women with preeclampsia. Hypertens Pregnancy. 2007; 26:415-421. 